\title{
Associations between treatment goals, patient characteristics, and outcome measures for patients with musculoskeletal disorders in physiotherapy practice
}

\author{
Olav Amundsen ${ }^{1 *}$, Nina Køpke Vøllestad', Ingebrigt Meisingset ${ }^{2}$ and Hilde Stendal Robinson ${ }^{1}$
}

\begin{abstract}
Background: Goal setting is linked to person-centred care and is a core component in physiotherapy, but the associations between goal classes, patient characteristics and outcome measures for musculoskeletal disorders has not been investigated. The study's purpose was to examine 1) how goals used in clinical practice for patients with musculoskeletal disorders (MSD) are distributed in classes based on ICF, 2) if goal classes were associated with patient characteristics and 3) whether goal classes were associated with treatment outcome.

Methods: Data analysis from a longitudinal observational study ( $N=2591)$. Goals were classified in symptom, function/structure, activity/participation and non-classifiable. Associations between patient characteristics and goal classes were examined using $x^{2}$ and one-way ANOVA. Association between goal classes and outcomes were examined using multiple logistic and linear regression models. Outcomes are reported at 3 months or end of treatment if prior to 3 months.
\end{abstract}

Results: There was a high variability in goals used for patients with MSD. 17\% had symptom goals, 32.3\% function/ structure, $43.4 \%$ activity/participation and 7.4\% non-classifiable goals. We found significant associations between goal classes and age, gender, severity, region of pain/diagnosis and emotional distress (all $p<.001$ ). Activity/ participation goals were associated with better outcomes on GPE (OR 1.80, 95\% Cl 1.23-2.66). Non-classifiable goal was associated with poorer outcomes on pain intensity (B .87, 95\% Cl .32-1.43).

Conclusion: There is an association between goal classes and patient characteristics. Including activity/participation in the main goal was associated with better outcomes for GPE and having a non-classifiable goal was associated with poorer outcomes for pain intensity.

Trial registration: The project is approved by the Regional committee for Medical and Health Research Ethics in Norway (REC no. 2013/2030). https://clinicaltrials.gov/ct2/show/NCT03626389.

\footnotetext{
* Correspondence: olavamu@gmail.com

${ }^{1}$ Institute of Health and Society, Faculty of Medicine, University of Oslo, P. O box 1130 Blindern, 0318 Oslo, Norway

Full list of author information is available at the end of the article
}

C C The Author(s). 2021 Open Access This article is licensed under a Creative Commons Attribution 4.0 International License, which permits use, sharing, adaptation, distribution and reproduction in any medium or format, as long as you give appropriate credit to the original author(s) and the source, provide a link to the Creative Commons licence, and indicate if changes were made. The images or other third party material in this article are included in the article's Creative Commons licence, unless indicated otherwise in a credit line to the material. If material is not included in the article's Creative Commons licence and your intended use is not permitted by statutory regulation or exceeds the permitted use, you will need to obtain permission directly from the copyright holder. To view a copy of this licence, visit http://creativecommons.org/licenses/by/4.0/. The Creative Commons Public Domain Dedication waiver (http://creativecommons.org/publicdomain/zero/1.0/) applies to the data made available in this article, unless otherwise stated in a credit line to the data. 


\section{Introduction}

Musculoskeletal disorders (MSD) are a major social and economic burden and the leading cause of years lived with disability worldwide [1]. A systematic review of clinical guidelines for MSD endorse the use of person-centred care within a biopsychosocial model with the use of effective communication and shared decision-making, and recommend providing individualised care based on the persons context and preference [2]. The identification and setting of treatment goals with patients is clearly linked to person-centred care [3] and is regarded as a core component in the treatment process [4].

Previous research has shown that goals of physiotherapy interventions can be described using the The International Classification of Functioning, Disability and Health (ICF) [5]. One study in physiotherapy practice have indicated that person-centred meaningful treatment goals should correspond to the classification level of activity and participation in The International Classification of Functioning, Disability and Health (ICF) [3]. Furthermore, it is recommended to focus goal setting in clinical practice around behaviour related to activity and participation in ICF, rather than reporting of internal experiences, such as pain [6]. Studies of treatment goals used by patients with MSD show different results. Some studies have found that most patients define goals orientated towards activity, participation and coping [7] while others found higher use of symptom-focused goals [811]. The variation in goal classes might be explained by differences in patient characteristics and treatment settings, as there were important differences in age, employment, duration, diagnosis and recruitment settings between the studies.

Demographic, anthropometric, psychosocial and disease-specific factors are associated with outcomes for patients with MSD [12-19], and psychosocial factors have been shown to influence the goal setting process, engagement in goals, goal pursuit and goal conflicts [20-22]. Previous research has indicated that high symptom focus might prevent patients from reaching non-symptom related goals [9] and symptom distress is associated with less progression towards goals [23]. This suggests that a wide range of factors is important both for goal setting, goal pursuit and its relation to outcomes.

Previous studies have reported the association between goals, psychosocial factors [12-19] and their relation to outcomes $[9,23]$. Despite this, we were not able to identify any studies that have compared the use of different goal classes and the associations between outcomes for patients with MSD. Furthermore, there is a lack of research on how patient characteristics are associated with treatment goals and how classifications of goals are associated with outcome measures.
We wanted to explore 1) how goals used in clinical practice for patients with MSD are distributed in classes based on domains of ICF, 2) if goal classes were associated with certain patient characteristics and 3) whether goal classes reflecting different domains of ICF were associated with treatment outcome.

\section{Methods}

\section{Study design, setting and data collection}

This cohort study is part of the Norwegian longitudinal observational project Physiotherapy in Primary Health Care (FYSIOPRIM). The project includes data from adult patients seeking physiotherapy in nine municipalities Norway. All patients seeking physiotherapy in the 36 participating clinics in the primary health care system were eligible for inclusion. Patients were invited to participate on their first encounter with a physiotherapist in primary health care and were given project information and consent forms. The patients were treated by 109 different physiotherapists. 74 were general physiotherapists, 21 specialised as manual therapists and 14 specialised as psychomotor physiotherapists. Baseline data was collected in two steps. First, data were registered by the physiotherapist and the patient in collaboration. They jointly agreed, and defined, the main treatment goal and scored the most important functional problems using the Patient-Specific Functional Scale (PSFS) [24]. The physiotherapist registered diagnosis and determined whether the patient should fill in any disease- or regionspecific questionnaires. Secondly, the patient completed questionnaires online. After 3 months or earlier if treatment was terminated before that, the physiotherapist and patient evaluated goal achievement and the patient completed the standardised outcome questionnaires. A more thorough description of the data collection for FYSIOPRIM and an overview of all recorded variables is presented in a previous article [25]. The full database included 4002 participants available for the present study, per 25.10.19. This study only included patients registered with a diagnosis related to the musculoskeletal system, excluding postoperative patients. A flowchart of the data collection process is presented in Fig. 1.

\section{Variables}

For this study we included the following variables: treatment goal, body region/diagnosis, and demographic, anthropometric, psychosocial and disease specific variables previously shown to be associated to outcomes for MSD [12-19]. The demographic variables were age, gender and education (high school or less, up to four years of higher education or more than four years of higher education) and the anthropometric variable was BMI. Psychosocial variables were emotional distress, measured by Hopkins Symptom Checklist 10 (HSCL10), [26] and 


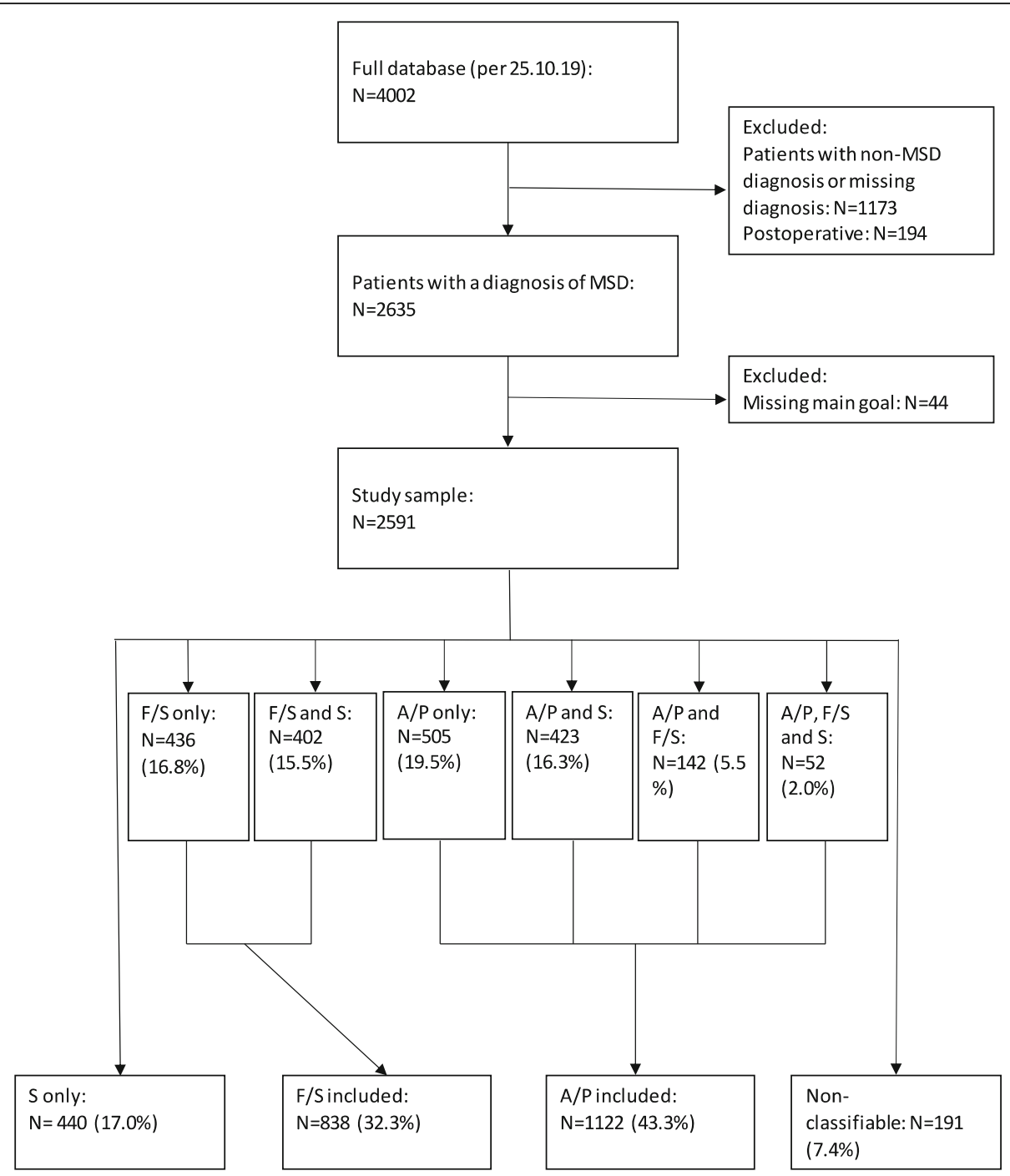

Fig. 1 Flowchart showing inclusion of patients and categorizing of goal classes. MSD = Musculoskeletal disorders. $S=$ Symptom. $\mathrm{F} / \mathrm{S}=$ Function/structure. $\mathrm{A} / \mathrm{P}=$ Activity $/$ participation

belief in effect of treatment measured by asking about agreement to the statement "I believe physiotherapy will improve my condition" (totally agree, agree, neither agree nor disagree, disagree or totally disagree). The disease-specific variables were duration of pain (first question on Short-Form Örebro; 0-1 weeks, 1-2 weeks, 3-4 weeks, 4-5 weeks, 6-8 weeks, 9-11 weeks, 3-6 months, 6-9 months, 9-12 months, over 1 year. Recoded to "less than 3 months", "3-12 months" and "more than 12 months") and severity (generated by average of pain last week (0-10, higher is more pain) and rating of the first activity on PSFS $(0-10$, higher is poorer self-rated ability on chosen activity).

The outcome measures were Global Perceived Effect 7 -point scale (GPE) (Since the start of treatment, my current overall status is: $1=$ very much better, $2=$ much better, $3=$ slightly better, $3=$ neither better or worse, $5=$ slightly worse, $6=$ much worse, $7=$ very much worse) [27], self-evaluated achievement of main goal (achieved, partly achieved or not achieved), change in PSFS and pain intensity after 3 months.

\section{Goal classes}

Before statistical analysis could be conducted, the treatment goals were coded based on definitions of the goal being symptom related, function or structure related, activity or participation related, combinations of these or being non-classifiable. Definitions were based on the main categories from ICF [28], as follows: Function is defined as "physiological functions of body systems". Structure is defined as "anatomical parts of the body such as organs, limbs and their components". The definition of activity is "the execution of a task or action by an individual" and the definition for participation is 
"involvement in a life situation". Symptoms such as pain are coded under body function in ICF. However, as previous research has suggested that symptom focused goals might affect outcome measures [9] and it has been recommended to not set goals related to internal experiences such as pain [6], we created a separate category directly related to symptoms. The goal classes were recoded, based on 1) goal including symptom, 2) goal including function or structure, 3) goal including activity or participation or 4) goal neither including activity, function nor symptom. This fourth class was termed "non-classifiable". Patients without a defined treatment goal were excluded. The recoding of goals is illustrated in Fig. 1.

\section{Statistical method}

Descriptive data are presented as frequencies and percentages or means and standard deviations as appropriate. Chi-square were used to examine univariable associations between categorical variables. One-way analysis of variance (ANOVA) with post hoc bonferroni test were used to examine associations between continuous variables.

To examine the associations between different goal classes and response on different treatment outcome measures, univariate logistic and linear regression analysis were used with $95 \%$ confidence intervals (CI). The assumptions of regression analysis were assessed. Multiple logistic and linear regression models were then used to control for demographic (age and gender), anthropometric (BMI), psychosocial (belief in effect of physiotherapy and emotional distress) and diseasespecific variables (severity, pain duration and body region/diagnosis). All variables were examined in the univariate models. The variables that were statistically significant at the $20 \%$ level $(p<0.20)$ were included in the multiple regression models. A backward manual elimination method was used to remove those variables with the highest $p$-value. The elimination was repeated until only variables statistically significant at the $5 \%$ level $(p<0.05)$ remained. To prevent elimination of a variable at one step in the analysis process being crucial, the variables removed on backward elimination were all reentered in the models one by one and remained in the models if they were statistically significant at the 5\% level. Goal class, age and gender were kept in the multiple regression models regardless of significance.

To allow logistic regression, GPE and self-evaluated improvement on main goal were coded into a dichotomous scale. The GPE 7-point scale was divided into "improved" and "not improved", where "improved" included the response of very much improved or much improved. "Not improved" included responses ranging from minimally improved to very much worse $[27,29]$. For self- evaluated achievement of main goal, reports of main goal being achieved was categorized as "achieved", and reports of main goal being partly achieved or not achieved was categorized as "not achieved". Linear regression was used for PSFS and pain intensity. As we had a large database and the data material was already collected before this study started, a sample size analysis was not conducted. A common model to calculate sample size would be the formula $N>50+8 \mathrm{~m}$ ( $\mathrm{m}=$ number of independent variables) for sample size calculations for multiple regressions. The lowest number of observations for one multiple regression analysis in our study was 975. This shows that the sample size was sufficient for the multiple regression analyses.

All statistical analysis was performed with IBM SPSS Statistics 25.

\section{Results}

Figure 1 presents results from categorizing goals and the baseline characteristics of the total sample and the four goal classes are given in Table 1. Examples of goals from the dataset for activity/participation are "be able to walk and run as before injury", "go hiking" and "get back to work" and examples of function/structure goals are "improved strength and range of motion" and "better knee function". Symptom only goals examples are "pain reduction", "pain relief" and "symptom absolution". Examples of goals that could not be classified are "get well", "get better" and "not getting worse".

Differences in patient characteristics between goal classes There were statistically significant differences between goal classes for the following baseline characteristics: age, gender, severity, body regions and emotional distress (all $p<.001)$ (Table 1 ).

The group with symptom only goals had patients with younger age ( $\mathrm{p}<.001$ compared to all other goal classes), more females (10.3\% more than EC), more patients with spinal pain (65.4\% higher than EC) and more unspecific/ multisite conditions (46.2\% higher than EC). Fewer patients in this group totally agreed in that they believed in effect of physiotherapy for their condition (17.4\% less than EC) and more patients neither agreed nor disagreed (52.6\% higher than EC). The group including function/ structure related goals had more patients with upper extremity pain (37.8\% higher than EC). The group with activity/participation goals had more males $(10.3 \%$ higher than EC), more patients with lower extremity pain (25.4\% higher than EC) and less patients scoring neither agree nor disagree to belief in effect of physiotherapy for their condition (19.2\% less than EC). The group with non-classifiable goals had more females $(10.4 \%$ higher than EC), more patients with unspecific/multisite conditions (171.7\% higher than EC) and higher emotional 
Table 1 Baseline patient characteristics and outcomes for the total study sample and for the four groups based on goal classes. Mean (SD) or N (\%)

\begin{tabular}{|c|c|c|c|c|c|c|}
\hline & $\begin{array}{l}\text { Total } \\
N=2591 \\
(100 \%)\end{array}$ & $\begin{array}{l}\text { Symptom only } \\
N=440(17.0 \%)\end{array}$ & $\begin{array}{l}\text { Function/structure } \\
\text { included } N=838 \\
(32.3 \%)\end{array}$ & $\begin{array}{l}\text { Activity/participation } \\
\text { included } N=1122 \\
(43.3 \%)\end{array}$ & $\begin{array}{l}\text { Non-classifiable } \\
N=191(7.4 \%)\end{array}$ & $P$ \\
\hline \multicolumn{7}{|l|}{ Characteristics } \\
\hline Age years, mean (SD) & $48.4(18.1)$ & $42.4(16.9)^{b c d^{*}}$ & $52.0(16.8))^{a c^{*}}$ & $47.5(18.8) a^{a^{*}}$ & $50.9(17.9) \mathrm{a}^{*}$ & $<.001$ \\
\hline Gender female, N (\%) & $\begin{array}{l}1763 \\
(69.5)\end{array}$ & $330(76.7)$ & $563(68.1)$ & $723(66.5)$ & $147(77.4)$ & $<.001$ \\
\hline BMI, mean (SD) & $26.6(10.4)$ & $25.5(4.9)$ & $27.3(13.1)$ & $26.6(10.2)$ & $25.8(4.5)$ & .092 \\
\hline Severity $(0-10) N(\%)$ & $5.3(1.7)$ & $5.0(1.7) \mathrm{c}^{*}$ & $5.3(1.6)$ & $5.5(1.7)^{\mathrm{a}^{*}}$ & $5.4(1.6)$ & $<.001$ \\
\hline Body region/diagnosis N (\%) & & & & & & $<.001$ \\
\hline Spinal & $750(28.9)$ & $211(47.7)$ & $220(25.8)$ & $259(23.5)$ & $60(30.0)$ & \\
\hline Upper extremities & $504(19.4)$ & $68(15.4)$ & $228(26.7)$ & $187(17.0)$ & $21(10.5)$ & \\
\hline Lower extremities & $\begin{array}{l}1118 \\
(43.0)\end{array}$ & $107(24.2)$ & $344(40.3)$ & $595(53.2)$ & $72(36.0)$ & \\
\hline Unspecific/ multisite conditions & $225(8.7)$ & $56(12.7)$ & $61(7.2)$ & $61(5.5)$ & $47(23.5)$ & \\
\hline $\begin{array}{l}\text { Emotional distress (HSCL10, score 1-4), } \\
\text { mean (SD) }\end{array}$ & $1.62(.51)$ & $1.66(.51)^{d^{*}}$ & $1.60(.49)^{\mathrm{d}^{*}}$ & $1.60(.50)^{d^{*}}$ & $1.86(.61) a^{a b c *}$ & .001 \\
\hline Treatment beliefs, N (\%) & 1776 & & & & & .021 \\
\hline Totally agree & $994(56.0)$ & $128(46.2)$ & $332(59.0)$ & $466(57.5)$ & $68(54.4)$ & \\
\hline Agree & $658(37.0)$ & $120(43.3)$ & $194(34.5)$ & $299(36.9)$ & $45(36.0)$ & \\
\hline Neither agree nor disagree & $122(6.9)$ & $29(10.5)$ & $36(6.4)$ & $45(5.5)$ & $12(9.6)$ & \\
\hline Disagree & $2(0.1)$ & $0(0)$ & $1(0.2)$ & $1(0.1)$ & $0(0)$ & \\
\hline Duration, N (\%) & 1817 & & & & & .575 \\
\hline$<3 m$ & $386(21.2)$ & $77(24.1)$ & $119(19.6)$ & $162(21.8)$ & 28 (19.2) & \\
\hline $3-12 m$ & $518(28.5)$ & 85 (26.6) & $170(28.0)$ & $222(29.9)$ & $41(28.1)$ & \\
\hline$>12 m$ & $913(50.2)$ & $158(49.4)$ & $319(52.5)$ & $359(48.3)$ & $77(52.7)$ & \\
\hline Education, N (\%) & 2072 & & & & & .350 \\
\hline High school or less & $826(39.9)$ & $124(36.5)$ & $276(40.5)$ & $374(41.5)$ & $52(34.9)$ & \\
\hline Up to $4 y$ higher seducation & $663(32.0)$ & $118(34.7)$ & $211(31.8)$ & $276(30.6)$ & $58(38.9)$ & \\
\hline 4y higher education sor more & $583(28.1)$ & $98(28.8)$ & $195(28.6)$ & $251(27.9)$ & $39(26.2)$ & \\
\hline \multicolumn{7}{|l|}{ Outcome measures } \\
\hline Global perceived effect - Improved & $900(65.0)$ & $122(55.5)$ & $290(64.2)$ & $429(71.1)$ & $59(54.1)$ & $<.001$ \\
\hline Main goal achieved & $439(42.6)$ & $64(42.7)$ & $123(37.4)$ & $201(45.8)$ & $51(50.0)$ & .081 \\
\hline PSFS change ( -10 to 10$)$ & $2.94(2.98)$ & $2.61(2.96)$ & $3.05(2.94)$ & $3.13(3.04) \mathrm{d}^{*}$ & $2.23(2.7)^{c^{*}}$ & .022 \\
\hline Pain intensity change ( -10 to 10$)$ & $\begin{array}{l}-1.12 \\
(2.40)\end{array}$ & $-1.19(2.36)^{d^{*}}$ & $-0.98(2.35)$ & $-1.34(2.41)^{d^{*}}$ & $-0.31(2.43)^{a c^{*}}$ & $<.001$ \\
\hline
\end{tabular}

M Mean, SD Standard deviation, HSCL10 Hopkins Symptom Check List 10 item version, higher is worse. Severity = average of pain intensity last week (0-10) and inverted rating of PSFS (0-10), higher is worse. $y=$ years, $m=$ months. $P=X^{2} /$ ANOVA. ${ }^{a}$ : compared to symptom, ${ }^{b}$ : compared to function/structure, ${ }^{c}$ : compared to activity/participation, ${ }^{\text {: }}$ compared to non-classifiable. *: post hoc bonferroni $\leq .05$

distress $(p<.001$ compared to other goal classes). This group also had more people scoring neither agree nor disagree to belief in effect of physiotherapy for their condition (39.5\% higher than EC).

\section{Associations between treatment outcomes and goal classes}

Table 2, 3, 4 and 5 shows the crude and adjusted associations between the four different treatment outcomes and goal classes together with patient characteristics. After 3 months, 1384 patients had filled out GPE and 1031 patients reported on achievement of treatment goal after. For PSFS, 975 patients reported after 3 months, while 1273 patients reported on pain intensity after 3 months.

Compared to the goal class symptom, the goal class Activity/participation was associated with improvement on the GPE $(\mathrm{OR}=1.80 ; 95 \% \mathrm{CI}=1.23-2.66)$ in the 
Table 2 Crude and adjusted odds ratios with 95\% confidence intervals (Cl) for global perceived effect (GPE), dichotomized in improved (1-2) and not improved (3-7) and goal classes and demographical, anthropometric, psychosocial and disease-specific variables. Odds ratio $>1$ indicates higher odds for reporting improved. $N=1384$

\begin{tabular}{|c|c|c|c|c|}
\hline Variable & $\begin{array}{l}\text { Crude estimates } \\
\text { OR }(95 \% \mathrm{CI})\end{array}$ & $\mathrm{p}$ & $\begin{array}{l}\text { Multiple regression } \\
\text { model OR }(95 \% \mathrm{CI})\end{array}$ & $\mathrm{p}$ \\
\hline Goal classes & & $<.001$ & & .008 \\
\hline Symptom only & Reference & & Reference & \\
\hline Function/structure included & 1.44 (1.04 to 2.00$)$ & .030 & $1.22(.81$ to 1.84$)$ & .337 \\
\hline Activity/participation included & 1.98 (1.44 to 2.72$)$ & $<.001$ & $1.80(1.23$ to 2.66$)$ & .004 \\
\hline Non-classifiable & $.95(.60$ to 1.50$)$ & .768 & 1.15 (.66 to 2.00$)$ & .791 \\
\hline Age (years) & .99 (.99 to 1.00$)$ & .037 & .99 (.98 to 1.00$)$ & .054 \\
\hline Gender (male is reference) & 1.01 (.79 to 1.29$)$ & .914 & $.82(.62$ to 1.09$)$ & .112 \\
\hline $\mathrm{BMl}$ & $1.00(.99$ to 1.02$)$ & .592 & & \\
\hline Treatment belief ${ }^{a}$ & & $<.001$ & & $<.001$ \\
\hline Totally agree & Reference & & Reference & \\
\hline Agree & $.44(.34$ to. .57$)$ & $<.001$ & .49 (.37 to .64$)$ & $<.001$ \\
\hline Neither agree nor disagree & .29 (.18 to.47) & $<.001$ & $.35(.21$ to .58$)$ & $<.001$ \\
\hline Emotional distress (HSCL10, score 1-4), & $.44(.35$ to. .56$)$ & $<.001$ & $.50(.38$ to .66$)$ & $<.001$ \\
\hline Severity (score 0-10) & $.95(.88$ to 1.01$)$ & .108 & & \\
\hline Duration & & $<.001$ & & \\
\hline$<3$ months & Reference & & & \\
\hline $3-12$ months & $1.0(.68$ to 1.46$)$ & .986 & & \\
\hline$>12$ months & $.62(.44$ to.86) & .004 & & \\
\hline Body region/diagnosis & & $<.001$ & & .056 \\
\hline Spinal & Reference & & Reference & \\
\hline Upper extremities & 1.46 (1.05 to 2.03$)$ & .026 & $1.17(.79$ to 1.73$)$ & .435 \\
\hline Lower extremities & $1.34(1.02$ to 1.76$)$ & .034 & $1.03(.74$ to 1.43$)$ & .856 \\
\hline Unspecific/multisite conditions & .54 (.36 to.80) & .003 & .59 (.37 to .94$)$ & .027 \\
\hline
\end{tabular}

OR Odds radio, Cl Confidence intervals, HSCL10 Hopkins Symptom Check List 10 item version. Severity = average of pain intensity last week (0-10) and inverted rating of PSFS (0-10), higher is worse

${ }^{a}$ : One patient answered disagree and one patient answered totally disagree. Data not presented in table due to low number

multiple logistic regression analysis. In addition, lower age, more positive treatment beliefs and lower emotional distress was associated with improvement, while having unspecific/multisite pain were associated with less improvement.

There were no association between goal classes and self-evaluated achievement of treatment goal in the univariate or multiple logistic regression analysis (Table 3). Lower emotional distress, lower severity and duration less than 3 months were significantly associated with achieved treatment goal.

Similarly, there were no association between goal classes and PSFS used as outcome (Table 4). In the multiple linear regression analysis lower age, being female, answering totally agree in belief of effect of physiotherapy, lower emotional distress, higher severity rating and having upper extremity pain compared to spinal pain were significantly associated with better scores on the PSFS.
When pain intensity was used as outcome, non-classifiable goal was associated with less improvement with a B-value of .87 (Table 5) in the multiple linear regression analysis. In addition, higher age, lower severity, and unspecific/multisite pain were significantly associated with less improvement.

\section{Discussion}

We found high variability in what treatment goals were used for patients with MSD seeking physiotherapy in primary health care in Norway. We found an association between goal classes and the patient characteristics; age, gender, severity, body region/diagnosis and emotional distress. The group with symptom only goals had significantly younger age, more females, more patients with spinal pain and unspecific/multisite pain and also fewer patients having a high belief in the effect of physiotherapy. The group with function/structure goals had more patients with upper extremity pain. In the group of 
Table 3 Crude and adjusted odds ratios with 95\% confidence intervals (Cl) for self-evaluated improvement on main goal, dichotomized in improved (achieved main goal) and not improved (partly achieved or not achieved) and goal classes and demographical, anthropometric, psychosocial and disease-specific variables. Odds ratio > 1 indicates higher odds for reporting improved. $N=1031$

\begin{tabular}{|c|c|c|c|c|}
\hline Variable & $\begin{array}{l}\text { Crude estimates } \\
\text { OR }(95 \% \mathrm{Cl})\end{array}$ & $p$ & $\begin{array}{l}\text { Multiple regression } \\
\text { model OR }(95 \% \mathrm{Cl})\end{array}$ & $\mathrm{p}$ \\
\hline Goal classes & & .082 & & .066 \\
\hline Symptom only & Reference & & Reference & \\
\hline Function/structure included & $.80(.54$ to 1.19$)$ & .272 & $.59(.34$ to 1.00$)$ & .051 \\
\hline Activity/participation included & $1.09(.75$ to 1.58$)$ & .669 & $.87(.53$ to 1.45$)$ & 611 \\
\hline Non-classifiable & $1.34(.81$ to 2.23$)$ & .252 & 1.14 (.58 to 2.24$)$ & .708 \\
\hline Age & $.99(.99$ to 1.00$)$ & .112 & $1.00(.99$ to 1.01$)$ & .968 \\
\hline Gender & 1.33 (1.01 to 1.77$)$ & .040 & 1.16 (.78 to 1.72$)$ & .455 \\
\hline BMl & $.99(.97$ to 1.01$)$ & .176 & & \\
\hline Treatment belief $^{a}$ & & .076 & & \\
\hline \multicolumn{5}{|l|}{ Totally agree } \\
\hline Agree & $.70(.51$ to .96$)$ & .024 & & \\
\hline Neither agree nor disagree & $.58(.31$ to 1.08$)$ & .085 & & \\
\hline Emotional distress (HSCL10, score 1-4), & $.51(.38$ to .69$)$ & $<.001$ & $.58(.40$ to .85$)$ & .005 \\
\hline Severity (score 0-10) & $.84(.77$ to .91$)$ & $<.001$ & $.88(.80$ to .99$)$ & .025 \\
\hline Duration & & $<.001$ & & .009 \\
\hline$<3 m$ & Reference & & Reference & \\
\hline $3-12 m$ & .48 (.32 to .73) & .001 & $.54(.33$ to .86$)$ & .009 \\
\hline$>12 m$ & $.51(.35$ to .73$)$ & $<.001$ & .54 (.35 to .82) & .004 \\
\hline Body region/diagnosis & & .004 & & \\
\hline Spinal & Reference & & & \\
\hline Upper extremities & $.84(.57$ to 1.23$)$ & .371 & & \\
\hline Lower extremities & $.74(.55$ to 1.00$)$ & .050 & & \\
\hline Unspecific/multisite conditions & $.40(.24$ to .66$)$ & $<.001$ & & \\
\hline
\end{tabular}

OR Odds radio, $\mathrm{Cl}$ Confidence intervals, HSCL10 = Hopkins Symptom Check List 10 item version. Severity = average of pain intensity last week (0-10) and inverted rating of PSFS (0-10), higher is worse

${ }^{a}$ : Two patients answered disagree. Data not presented in table due to low number

activity/participation goals there were more males, more patients with pain in their lower extremities and less patients with a lower belief in the effect of physiotherapy. The group with non-classifiable goals had more females, more patients with unspecific/multisite pain and significantly higher emotional distress. The group also had a lower belief in effect of physiotherapy.

Our results show that including activity and/or participation in the main goal was associated with better outcomes for GPE, while having a non-classifiable goal was associated with poorer outcomes for pain intensity. However, the effects were small.

\section{Goal classes for MSD}

We found large variability of goals for patients with MSD when classifying goals based on the main domains of ICF and a symptom class. About half the goals could be classified into a single domain, while $7.4 \%$ of the goals were non-classifiable in our classifying system. This was mainly because of the goals being too broad and general. Our study allowed the goal setting process to be controlled by the therapist and patient alone without giving information on how the goals would be classified or how to conduct the goal setting process. This allowed the goal setting to be influenced mainly by therapist and patient characteristics. The high variability in goals were therefore as we expected as previous research indicates that both different therapist and patient characteristics are likely to influence goal setting $[7,9,30]$.

Our findings are comparable to previous studies. We found that close to $30 \%$ of patients with spinal pain reported a main goal orientated around symptoms alone. Similar to our finding, Van Dulmen et al. (2016) found that more than $70 \%$ of patients with spinal pain chose reduction of pain as one of their goals for physiotherapy treatment. In contrast to this finding, Gardner et al. 
Table 4 Crude and adjusted B-value with 95\% Cl for change in Patient Specific Functional Scale (PSFS) (- 10 to 10, higher is better) from baseline to 3 months, goal classes, demographical, anthropometric, psychosocial and disease-specific variables. B $>0$ indicates better outcome. $N=975$

\begin{tabular}{|c|c|c|c|c|}
\hline Variable & $\begin{array}{l}\text { Univariate regression } \\
\mathrm{B}(95 \% \mathrm{Cl})\end{array}$ & $p$ & $\begin{array}{l}\text { Multiple regression } \\
\text { model B }(95 \% \mathrm{Cl})\end{array}$ & $\mathrm{p}$ \\
\hline \multicolumn{5}{|l|}{ Goal classes } \\
\hline Symptom only & Reference & & Reference & \\
\hline Function/structure included & $.44(-.12$ to .99$)$ & .126 & $.35(-.25$ to .96$)$ & .249 \\
\hline Activity/participation included & $.52(.02$ to 1.05$)$ & .057 & $.16(-.42$ to .74$)$ & 589 \\
\hline Non-classifiable & $-.51(-1.31$ to .30$)$ & .220 & $-.30(-1.17$ to .56$)$ & .492 \\
\hline Age & $-.02(-.03$ to .01$)$ & $<.001$ & $-.03(-.04$ to -.02$)$ & $<.001$ \\
\hline Gender & $.64(.23$ to 1.05$)$ & .002 & $.42(-.02$ to .86$)$ & .061 \\
\hline BMI & $-.01(-.03$ to.02) & .662 & & \\
\hline \multicolumn{5}{|l|}{ Treatment belief $^{a}$} \\
\hline Totally agree & Reference & & Reference & \\
\hline Agree & $-.54(-.99$ to -.08$)$ & .021 & $-.37(-.80$ to -.05$)$ & .082 \\
\hline Neither agree nor disagree & $-1.22(-2.10$ to -.34$)$ & .006 & $-1.10(-1.90$ to -.30$)$ & .007 \\
\hline Emotional distress (HSCL10, score 1-4), & $-.87(-1.28$ to -.47$)$ & $<.001$ & $-1.39(-1.81$ to -.97$)$ & $<.001$ \\
\hline Severity (score 0-10) & .52 (.41 to.64) & $<.001$ & $.66(.53$ to .78$)$ & $<.001$ \\
\hline \multicolumn{5}{|l|}{ Duration } \\
\hline$<3 m$ & Reference & & & \\
\hline $3-12 m$ & $.19(-.63$ to 1.02$)$ & .650 & & \\
\hline$>12 m$ & $.44(-.30$ to 1.17$)$ & .246 & & \\
\hline \multicolumn{5}{|l|}{ Body region/diagnosis } \\
\hline Spinal & Reference & & & \\
\hline Upper extremities & $.82(.28$ to 1.37$)$ & .003 & & \\
\hline Lower extremities & $.45(.01$ to .90$)$ & .048 & & \\
\hline Unspecific/multisite conditions & $-.44(-1.16$ to .29$)$ & .236 & & \\
\hline
\end{tabular}

Cl Confidence intervals, HSCL10 Hopkins Symptom Check List 10 item version. Severity=average of pain intensity last week (0-10) and inverted rating of PSFS (0$10)$, higher is worse

a: Two patients answered disagree and one patient answered totally disagree. Data not presented in table due to low number

(2015) showed that patients with chronic low back pain tend to set goals orientated around activity, participation and coping, and not symptoms alone. This contrast might be due to difference in recruitment setting as their study predominantly recruited non-care seeking participants from the community. It could also be due to the goal setting process, as their study included giving the patients preliminary information on the chronic pain model, self-management tips and goal setting before the patient filled in their goals.

We found interesting differences in use of goal classes between different body regions/diagnosis. Patients with spinal pain chose symptom related goals more than other patients, while patients with unspecific/multisite conditions had more non-classifiable goals. Patients with upper- or lower extremity pain used more goals related to function/structure or activity/participation. Henry et al. (2017) found that patients with chronic musculoskeletal pain who were prescribed long-term opioids, prioritized symptom relief as the most important goal. Most patients in their study had several pain sites, with lower back being reported by $75 \%$ and a substantial proportion had comorbid mental health diagnoses. This is somewhat comparable to our findings as most patients in their study would correspond to our categories of spinal pain or unspecific/multisite conditions, although we do not have information about the patients use of pain medication. This supports our finding that patients with spinal pain or unspecific/multisite conditions more often define treatment goals related to symptom relief. Our findings show that patients with MSD related to the extremities uses more goals related to function/structure and activity/participation, less symptom related goals and have less non-classifiable goals. This might indicate that it is easier for patients to set goals related to specific functions and activities when they have MSD related to their extremities compared to having spinal pain or an unspecific/multisite condition. 
Table 5 Crude and adjusted B-value with $95 \% \mathrm{Cl}$ for change in pain intensity (- 10 to 10, higher is worse) from baseline to 3 months, goal classes, demographical, anthropometric, psychosocial and disease-specific variables. B $>0$ indicates poorer outcome. $N=1273$

\begin{tabular}{|c|c|c|c|c|}
\hline Variable & $\begin{array}{l}\text { Univariate regression } \\
\mathrm{B}(95 \% \mathrm{Cl})\end{array}$ & $\mathrm{p}$ & $\begin{array}{l}\text { Multiple regression } \\
\text { model B }(95 \% \mathrm{Cl})\end{array}$ & $\mathrm{p}$ \\
\hline \multicolumn{5}{|l|}{ Goal classes } \\
\hline Symptom only & Reference & & Reference & \\
\hline Function/structure included & $.21(-.19$ to .60$)$ & .304 & .29 (-.09 to .68) & .137 \\
\hline Activity/participation included & $-.17(-.54$ to .21$)$ & .383 & $.08(-.30$ to .45$)$ & .676 \\
\hline Non-classifiable & .89 (.32 to 1.46$)$ & .002 & $.87(.32$ to 1.42$)$ & .002 \\
\hline Age & $.01(.01$ to .02$)$ & .002 & $.01(.01$ to .02$)$ & .001 \\
\hline Gender & $-.22(-.51$ to .06$)$ & .128 & $-.17(-.44$ to .11$)$ & .239 \\
\hline $\mathrm{BMl}$ & $.01(-.01$ to .02$)$ & .676 & & \\
\hline \multicolumn{5}{|l|}{ Treatment belief $^{a}$} \\
\hline Totally agree & Reference & & & \\
\hline Agree & $.19(-.11$ to .49$)$ & .218 & & \\
\hline Neither agree nor disagree & $-.01(-.58$ to .57$)$ & .989 & & \\
\hline Emotional distress (HSCL10, score 1-4), & $.24(-.03$ to .51$)$ & .082 & & \\
\hline Severity $(0-10)$ & $-.43(-.51$ to -.36$)$ & $<.001$ & $-.45(-.53$ to -.38$)$ & $<.001$ \\
\hline \multicolumn{5}{|l|}{ Duration } \\
\hline$<3$ months & Reference & & & \\
\hline $3-12$ months & $-.21(-.79$ to .37$)$ & .514 & & \\
\hline$>12$ months & $-.08(-.60$ to .43$)$ & .752 & & \\
\hline \multicolumn{5}{|l|}{ Body region/diagnosis } \\
\hline Spinal & Reference & & Reference & \\
\hline Upper extremities & $-.25(-.64$ to .13$)$ & .205 & $-.23(-.60$ to .14$)$ & .228 \\
\hline Lower extremities & $-.01(-.33$ to .31$)$ & .953 & $-.04(-.35$ to .27$)$ & .796 \\
\hline Unspecific/multisite conditions & $.81(.31$ to 1.33$)$ & .002 & $.91(.41$ to 1.39$)$ & $<.001$ \\
\hline
\end{tabular}

$\mathrm{Cl}$ Confidence intervals, HSCL10 Hopkins Symptom Check List 10 item version. Severity = average of pain intensity last week (0-10) and inverted rating of PSFS (0$10)$, higher is worse

${ }^{a}$ : Two patients answered disagree and one patient answered totally disagree. Data not presented in table due to low number

\section{Goal classes and patient characteristics}

It has been indicated that goals related to the activity and participation domain in the ICF, are the most meaningful and person-centred goals [3]. Still, only about $43 \%$ of the goals reported in our dataset included the activity and participation domain. One interpretation of this finding could be that in a population with large differences in patient characteristics, it is expected that the goals will vary as well. Indeed, our findings show that goal classes are associated with different patient characteristics such as age, gender, severity, body region/diagnosis and emotional distress. There is also support for this view in the literature as studies using different patient populations has found different results in terms of what goals they choose [7-10]. Further, a qualitative study on the meaning of recovery after a musculoskeletal injury found that patients summarised recovery either as complete symptom cessation and pain-free function or as return to function despite residual pain. Both the meaning of recovery and the expectations of recovery were influenced by several factors such as diagnosis, radiographic imaging, prior experiences, general health perceptions and own sense of resilience [31].

\section{Goal classes and outcomes}

We found an association between goal classes and GPE and pain intensity as outcome measures. Moreover, activity or participation related goals were associated with better outcomes on GPE and non-classifiable goals were associated with poorer outcomes for pain intensity. Previous studies on other patient groups have found comparable results, with improved outcomes for patients having goals comparable to activity or participation [3234]. They studied patients with stroke [32], depression [33] and vulvodynia [34], and suggested that associations with motivation, behaviour change and self-efficacy could be possible explanations. One study has found strong links between goal preferences and activity 
patterns for patients with widespread pain, and concluded that reinforcing achievement goals was recommended to improve chronic pain adaptation for patients with fibromyalgia [35]. Together with our findings, this shows there are associations between goal setting and outcomes for different patient groups and that this might be related to factors such as motivation, behaviour change and self-efficacy. Furthermore, this might indicate that a better understanding of goal setting and how this potentially could improve outcomes for MSD is important, and future research within this field is warranted.

We found that non-classifiable goals were associated to characteristics previously linked to poorer outcomes for MSD, such as being female, having high psychosocial distress and multisite or unspecific pain diagnosis [1218]. Furthermore, we also found that non-classifiable goals were associated with poorer outcomes on pain intensity. This could be seen as an example of the multidimensional complexity of MSD and that a multitude of factors seem to be interlinked and might become barriers to improvement. Goal setting is considered important to plan interventions, direct attention and for motivational purposes $[4,36]$, and our findings show that the type of goal can reflect certain baseline characteristics. Emerging evidence supports that MSD needs to be evaluated in a broad perspective [37] and shows there are certain phenotypes with increased risk for poorer outcomes [38]. We should be aware that patient goals might reflect some of the characteristics associated to poorer outcomes recommended to screen for in patients with MSD. This aspect should be considered especially in patients with non-classifiable goals, as these were associated with known prognostic factors for poorer outcomes, such as high emotional distress and multisite or unspecific pain diagnosis [12-18].

Interestingly, there were no association between goals and outcomes on PSFS or self-evaluated improvement on main goal. It could be expected that having a symptom related goal would be associated to less improvement on PSFS, as previous research has indicated that the pursuit of pain-related goals might negatively influence non-pain related goals [9]. However, we found no association between goal class and change on PSFS. Neither were there any association on self-evaluated achievement on main goal.

\section{Clinical implications}

Our results provide a broader understanding and more knowledge about patients' personalized goals for treatment. We found associations between goals, patient characteristics and outcomes as well as large variations in types of goals being important to patients. This knowledge can be useful for therapists in making more person-centred treatment plans.Strengths and limitations One strength of this study is the use of a large database including more than 2500 patients with MSD seeking physiotherapy in primary health care. This indicates that our results reflect clinical practice in primary health care in Norway.

There are also some limitations that should be considered. Firstly, there was a high number of dropouts that did not fill out outcomes at 3 months. 1207 patients did not fill out GPE at 3 months, 1560 patients for selfevaluated improvement on main goal, 1616 for PSFS and 1360 for pain intensity. Secondly, as the only instruction to the therapist was to set a main goal in collaboration with the patient, it is unknown whether there was an equal contribution in the goal setting process. Previous research has shown that there is a large variation in contribution between therapist and patient when setting treatment goals. Therapists with a biomedical treatment focus was associated with less patient involvement in goal setting compared with therapists with a biopsychosocial focus [30]. We do not have information on the therapist's treatment focus or the involvement of patients in goal setting and have consequently not been able to control for these factors.

\section{Conclusion}

We found large variability in goals used for patients with MSD seeking physiotherapy in primary health care in Norway. The content of goals were classified to the whole range of the domains of ICF, with only about one third restricted to either function or structure improvement or limitations in activity or participation. Most goals included a mix of domains. Less than $10 \%$ of the goals were not classifiable according to ICF. We found an association between goal classes and the patient characteristics; age, gender, severity, body region/diagnosis and emotional distress. Additionally, we found a weak association between goal classes and outcomes, where including activity and/or participation in the main goal was associated with better outcomes for GPE and having a non-classifiable goal was associated with poorer outcomes for pain intensity.

\section{Acknowledgments}

The authors would like to appreciate all physiotherapists involved in data collection through the FYSIOPRIM-project, and Marit Thielemann for coordinating the database.

\section{Authors' contributions}

O.A, N.K.V and H.S.R. developed research questions and hypothesis. O. A wrote the initial draft, and all authors were involved in revising it. O.A. led the data analyses with contributions from N.K.V. and H.S.R. All authors contributed to the interpretation of the data, commented critically on the manuscript, and read and approved the final manuscript. 


\section{Funding}

Norwegian Fund for Postgraduate training in Physiotherapy provided financial support through the FYSIOPRIM project.

\section{Availability of data and materials}

The data that support the findings of this study are available from Tjenester for Sensitive Data (TSD) but restrictions apply to the availability of these data, which were used under license for the current study, and so are not publicly available. Data are however available from the authors upon reasonable request and with permission of University of Oslo and (TSD).

\section{Ethics approval and consent to participate}

The project is conducted according to the Helsinki declaration and approved by the Regional committee for Medical and Health Research Ethics in Norway (REC no. 2013/2030). Project information and consent form were available in Norwegian and English. All patients have provided written informed consent to participate.

\section{Consent for publication}

Not applicable.

\section{Competing interests}

The authors declare that they have no competing interests.

\section{Author details}

${ }^{1}$ Institute of Health and Society, Faculty of Medicine, University of Oslo, P. O box 1130 Blindern, 0318 Oslo, Norway. ${ }^{2}$ Department of Public Health and Nursing, Norwegian University of Science and Technology (NTNU), Trondheim, Norway.

\section{Received: 26 October 2020 Accepted: 28 January 2021} Published online: 13 February 2021

\section{References}

1. Vos T, Abajobir AA, Abate KH, Abbafati C, Abbas KM, Abd-Allah F, et al. Global, regional, and national incidence, prevalence, and years lived with disability for 328 diseases and injuries for 195 countries, 1990-2016: a systematic analysis for the global burden of disease study 2016. Lancet. 2017;390(10100):1211-59.

2. Lin I, WL, Waller R, Goucke R, Nagree Y, Gibberd M, SL, Maher CG, O'Sullivan PPB. What does best practice care for musculoskeletal pain look like? Eleven consistent recommendations from high-quality clinical practice guidelines: systematic review. Br J Sports Med. 2020;54:79-86.

3. Melin J, Nordin A, Feldthusen C, Danielsson L. Goal-setting in physiotherapy: exploring a person-centered perspective. Physiother Theory Pract. 2019:118. https://doi.org/10.1080/09593985.2019.1655822. Epub ahead of print.

4. Wade DT. Goal setting in rehabilitation: an overview of what, why and how. Clin Rehabil. 2009;23(4):291-5.

5. Mittrach R, Grill E, Walchner-Bonjean M, Scheuringer M, Boldt C, Huber EO, et al. Goals of physiotherapy interventions can be described using the international classification of functioning. Disabil Health Physiother. 2008; 94(2):150-7.

6. Bovend'Eerdt TJ, Botell RE, Wade DT. Writing SMART rehabilitation goals and achieving goal attainment scaling: a practical guide. Clin Rehabil. 2009;23(4): 352-61

7. Gardner T, Refshauge K, McAuley J, Goodall S, Hubscher M, Smith L. Patient led goal setting in chronic low back pain-what goals are important to the patient and are they aligned to what we measure? Patient Educ Couns. 2015;98(8):1035-8.

8. Henry SG, Bell RA, Fenton JJ, Kravitz RL. Goals of chronic pain management: do patients and primary care physicians agree and does it matter? Clin J Pain. 2017:33(11):955-61.

9. Crombez G, Lauwerier E, Goubert L, Van Damme S. Goal pursuit in individuals with chronic pain: a personal project analysis. Front Psychol. 2016;7:966.

10. Lohman S, Decker J, Müller M, Strobl R, Grill E. The ICF Forms a Useful Framework for Classifying Individual Patient Goals in Post-Acute Rehabilitation. J Rehabil Med. 2011;43(2):151-5.

11. van Dulmen SA, van der Wees PJ, Bart Staal J, Braspenning JC. Nijhuis-van der Sanden MW. Patient reported outcome measures (PROMs) for goalsetting and outcome measurement in primary care physiotherapy, an explorative field study. Physiotherapy. 2017;103(1):66-72.

12. Verwoerd M, Wittink H, Maissan F, de Raaij E, Smeets R. Prognostic factors for persistent pain after a first episode of nonspecific idiopathic, nontraumatic neck pain: a systematic review. Musculoskelet Sci Pract. 2019;42: 13-37.

13. Chester R, Jerosch-Herold C, Lewis J, Shepstone L. Psychological factors are associated with the outcome of physiotherapy for people with shoulder pain: a multicentre longitudinal cohort study. Br J Sports Med. 2018;52(4): 269-75.

14. Hill JC, Fritz JM. Psychosocial influences on low back pain, disability, and response to treatment. Phys Ther. 2011;91(5):712-21.

15. lijima H, Aoyama T, Fukutani N, Isho T, Yamamoto Y, Hiraoka M, et al. Psychological health is associated with knee pain and physical function in patients with knee osteoarthritis: an exploratory cross-sectional study. BMC Psychol. 2018;6(1):19.

16. Artus M, Campbell P, Mallen CD, Dunn KM, van der Windt DA. Generic prognostic factors for musculoskeletal pain in primary care: a systematic review. BMJ Open. 2017;7(1):e012901.

17. Kindler LL, Jones KD, Perrin N, Bennett RM. Risk factors predicting the development of widespread pain from chronic back or neck pain. J Pain. 2010;11(12):1320-8.

18. Wijnhoven HAH, de Vet HCW, Picavet HSJ. Prevalence of musculoskeletal disorders is systematically higher in women than in men. Clin J Pain. 2006; 22(8):717-24.

19. Viester $L$, Verhagen VALM, Hengel KMO, Koppes LL, van der Beek AJ, Bongers PM. The relation between body mass index and musculoskeletal symptoms in the working population. BMC Musculoskelet Disord. 2013; 14(238):1-9.

20. Barclay L. Exploring the factors that influence the goal setting process for occupational therapy intervention with an individual with spinal cord injury. Aust Occup Ther J. 2002:49(1):3-13.

21. Moberly NJ, Dickson JM. Goal conflict, ambivalence and psychological distress: concurrent and longitudinal relationships. Personal Individ Differ. 2018;129:38-42.

22. Hardy JK, Crofford $\sqcup$, Segerstrom SC. Goal conflict, distress, and pain in women with fibromyalgia: a daily diary study. J Psychosom Res. 2011;70(6):534-40.

23. Clarke SP, Oades LG, Crowe TP, Caputi P, Deane FP. The role of symptom distress and goal attainment in promoting aspects of psychological recovery for consumers with enduring mental illness. J Ment Health. 2009: 18(5):389-97.

24. Moseng T, Tveter AT, Holm I, Dagfinrud H. The Patient-Specific Functional Scale - A useful tool for physiotherapists working in primary care. Fysioterapeuten. 2013;2:20-6.

25. Evensen KAI, Robinson HS, Meisingset I, Woodhouse A, Thielemann M, Bjorbaekmo WS, et al. Characteristics, course and outcome of patients receiving physiotherapy in primary health care in Norway: design of a longitudinal observational project. BMC Health Serv Res. 2018;18(1):936.

26. Derogatis LR, Lipman RS, Rickels K, Uhlenhuth EH, Covi L. The Hopkins symptom checklist (HSCL). A measure of primary symptom dimensions. Mod Probl Pharmacopsychiatry. 1974;7(0):79-110.

27. Kamper SJ, Maher CG, Mackay G. Global rating of change scales: a review of strengths and weaknesses and considerations for design. J Man Manip Ther. 2009:17(3):163-70

28. World Health Organization. International classification of functioning, disability and health (ICF). Geneva: WHO; 2001.

29. van der Roer N, Ostelo RW, Bekkering GE, van Tulder MW, de Vet HC. Minimal clinically important change for pain intensity, functional status, and general health status in patients with nonspecific low back pain. Spine (Phila Pa 1976). 2006:31(5):578-82.

30. Gardner T, Refshauge K, McAuley J, Hubscher M, Goodall S, Smith L. Goal setting practice in chronic low back pain. What is current practice and is it affected by beliefs and attitudes? Physiother Theory Pract. 2018;34(10):795-805.

31. Carrol LJ, Lis A, Weiser S, Torti J. How well do you expect to recover, and what does recovery mean, anyway? Qualitative study of expectations after a musculoskeletal injury. Phys Ther. 2016;96(6):797-807.

32. Ponte-Allan M, Giles GM. Goal setting and functional outcomes in rehabilitation. Am J Occup Ther. 1999:53(6):646-9. 
33. Wollburg E, Braukhaus C. Goal setting in psychotherapy: the relevance of approach and avoidance goals for treatment outcome. Psychother Res. 2010;20(4):488-94.

34. Rosen NO, Muise A, Bergeron S, Impett EA, Boudreau GK. Approach and avoidance sexual goals in couples with provoked Vestibulodynia: associations with sexual, relational, and psychological well-being. J Sex Med. 2015;12(8):1781-90.

35. Pastor-Mira MA, Lopez-Roig S, Martinez-Zaragoza F, Leon E, Abad E, Lledo A, et al. Goal preferences, affect, Activity Patterns and Health Outcomes in Women With Fibromyalgia. Front Psychol. 2019;10:1912.

36. Locke EA, Latham GP. Building a practically useful theory of goal setting and task motivation: a 35-year odyssey. Am Psychol. 2002;57(9):705-17.

37. Caneiro JP, Roos EM, Barton CJ, O'Sullivan K, Kent P, Lin I, et al. It is time to move beyond 'body region silos' to manage musculoskeletal pain: five actions to change clinical practice. Br J Sports Med. 2020;54:438-9.

38. Meisingset I, Vasseljen O, Vollestad NK, Robinson HS, Woodhouse A, Engebretsen KB, et al. Novel approach towards musculoskeletal phenotypes. Eur J Pain. 2020;24(5):921-32.

\section{Publisher's Note}

Springer Nature remains neutral with regard to jurisdictional claims in published maps and institutional affiliations.

- fast, convenient online submission

- thorough peer review by experienced researchers in your field

- rapid publication on acceptance

- support for research data, including large and complex data types

- gold Open Access which fosters wider collaboration and increased citations

- maximum visibility for your research: over $100 \mathrm{M}$ website views per year

At $\mathrm{BMC}$, research is always in progress. 